\title{
Study on Several Influencing Factors of Performance Evaluation Index of Photovoltaic System
}

\author{
Qingguo Xu, Hongbo Li, Guoqiang Hao, and Yefei Ding
}

\begin{abstract}
Based on previous study of photovoltaic system performance ratio (PR), this paper introduces our efforts in exploring the influencing factors which includes shadow, mismatch loss of series-parallel connection and dust. For photovoltaic systems, the performance ratio can be regarded as the evaluation index even though there is still no uniform evaluation standard in the industry. Actually, the study of performance ratio is focused on the photovoltaic system itself in some degree. Different factors influence the performance of photovoltaic systems in different degrees. We did several relevant researches by setting up an experimental platform and necessary contrast experiments have been done, such as different areas of shadow, different kinds of connection methods and so on. Through the algorithm of performance ratio, we did some analysis and some conclusions have been drawn which may be useful for the future design and evaluation of photovoltaic system.
\end{abstract}

Index Terms-Performance ratio, shadow, mismatch loss of series-parallel connection, photovoltaic systems.

\section{INTRODUCTION}

The development and application of new energy technology has drawn more and more attention with the worsening of environment and the deeper consciousness of human's environmental protection. Photovoltaic power generation is becoming more and more applied as one of the main green energy. In 2014, the new installed power capacity of photovoltaic market has reached $47 \mathrm{GW}$ and the totally installed capacity around the world is about $188.8 \mathrm{GW}$ [1]. At present, the intensified competition and international trade friction of PV industry have posed serious challenges to its development. Relying on technology, improving generating efficiency and reducing price of PV electricity have already become the consensus. Lots of factors including the meteorological factors as well as the electrical efficiency factors may affect the PV system output. Several shadow conditions which may be caused by buildings, trees, dust and pollutants in the process of generation exist on the PV array. The irradiance of modules received will be influenced so that the output characteristics of PV arrays have great changes. In addition, the phenomenon of series-parallel mismatch loss will be caused by these shadows on the modules as well as the

Manuscript received July 13, 2015; revised October 17, 2015.

Qingguo $\mathrm{Xu}$ is with East China University of Science and Technology, Shanghai, China (e-mail: qingguoxu@126.com).

Hongbo Li and Guoqiang Hao were with the Hareon Solar, Jiangyin, Jiangsu Province, China. Now, they are with East China University of Science and Technology, Shanghai, China (e-mail: lihongbo@ecust.edu.cn, haoguoqiang@ecust.edu.cn).

Yefei Ding is with Shanghai Solar Energy Research Center, Shanghai, China (e-mail: dingyefei@ solarcell.net.cn). hot spot effect with the design calculation and running of PV system.

Even though the photovoltaic power generation system is an important part of the new energy system in the future, many deficiencies including instability of electricity generation performance, huge influence by natural environment, and lack of evaluation methods in generation capacity and value exist. Nowadays, the performance evaluation index which is abbreviated as PR of PV system in the IEC 61724 [2], [3] has gained recognition of the industry. The index has nothing to do with the installed orientation of PV arrays, angle and quantity of irradiation on the array. Neither does the nominal installed capacity of PV arrays. It's a parameter that can contrast the performance of different photovoltaic power plants which are constructed in different locations and installed with different capacities. This kind of method could eliminate the influences of installed latitude and installed capacity so that the power attenuation, series-parallel mismatch loss, power transmission loss, and inverter loss can be represented comprehensively by one unified parameter.

There're several related researches on PV system. Muhammed J. et al. [4] indicated that power attenuation by dust as much as $50 \%$ can be experienced for solar PV modules that are left unclean for a period of over six months. Monto Mani et al. [5] discussed a framework to understand the various factors that govern the settling/assimilation of dust and likely mitigation measures. J.K. Kaldellis et al. [6] developed a theoretical model in order to be used as an analytical tool for obtaining reliable results concerning the expected effect of regional air pollution on PVs' performance. Besides, Emmanuel Kymakis et al. [7] analyzed a concrete grid connected photovoltaic park on the island of Crete and drew some conclusions. M. Z. Hussin et al. [8] presented a result obtained from a comparative study of three different photovoltaic (PV) module technologies for grid-connected (GC) system under Malaysia's operating conditions. However, there are seldom studies considering the quantitative analysis on the influence factors of performance ratio. Based on the previous basic theory we studied, we set up an experimental platform. We carried through analysis and research on the influence factors including loss of shadow, series-parallel mismatch, and dust on performance ratio in this paper.

\section{BASIC THEORETICAL MODEl AND DESIGN OF EXPERIMENTS}

\section{A. Performance Ratio $-P R$}

In the IEC 61724 [2], [3], the calculation of "Performance Ratio - PR" can be expressed as (1) and (2). 


$$
\begin{gathered}
\mathrm{PR}=\sum_{k}\left(P_{\text {out }} \times \tau_{k}\right) / \sum_{k} \frac{\left(C_{k} \times P_{0}\right) \times G_{i, k} \times \tau_{k}}{G_{i, \text { ref }}} \\
C_{k}=1+\gamma \times\left(T_{\text {mod }, k}-T_{\text {ref }}\right)
\end{gathered}
$$

where:

$P_{\text {out }, k}$ : During the evaluation period, at the $k^{\text {th }}$ unit time point, the real-time power of photovoltaic power system $(\mathrm{kW})$;

$P_{0}$ : The nominal power of $\mathrm{PV}$ array under specific temperature and irradiance $\left(25^{\circ} \mathrm{C}, 1000 \mathrm{~W} / \mathrm{m}^{2}\right.$, generally) $(\mathrm{kW})$;

$G_{i, k}$ : During the evaluation period, at the $\mathrm{k}^{\text {th }}$ unit time point, the irradiance radiated on the surface of $\mathrm{PV}$ arrays $\left(\mathrm{kW} \cdot \mathrm{h} \cdot \mathrm{h}^{-1} / \mathrm{m}^{2}\right)$;

$G_{i, \text { ref }}$ : Reference irradiance corresponding to $P_{0}\left(\mathrm{~kW} / \mathrm{m}^{2}\right)$;

$\gamma$ : The relative temperature coefficient of photovoltaic modules $\left(\% /{ }^{\circ} \mathrm{C}\right)$.

In the calculation equation of $\mathrm{PR}$, the numerator is the real electric energy production which is measured by devices and the denominator is the nominal electric energy production which can be calculated by integration of nominal generated output, the equation of nominal generated output is as (3).

$$
P=\frac{C_{k} \times P_{0} \times G_{i, k}}{G_{i, r e f}}
$$

Analyze the parameters source briefly:

$C_{k}$ - Typical samples that represent all the modules of the same lot tested in laboratory;

$G_{i, k}$ - Gathered by irradiance meter in real time;

$G_{i, r e f}, P_{0}$ - Lots of theoretical possibilities exist, STC conditions used commonly, nominal power and $1000 \mathrm{~W} / \mathrm{m}^{2}$ can be taken respectively.

Equation (4) can be elicited from (1) and (2).

$$
\mathrm{PR}=\frac{\int_{0}^{t_{0}} P_{\text {out }} d t}{\int_{0}^{t_{0}} P_{n}(t) d t}
$$

$P_{\text {out }}$ : The real output power of photovoltaic system, during the evaluation period $\mathrm{t}_{0}$, at the certain unit time point.

$P_{n}(t)$ : The sum of nominal generated power of each module, during the evaluation period $t_{0}$, at the certain unit time point.

We have had derivatives of numerator and denominator simultaneously in the calculation equation "Performance Ratio-PR" and introduced the idea of transient performance evaluation index $\operatorname{PR}\left(t_{0}\right)$ which can be regarded as the parameter to evaluate the transient performance of photovoltaic power station. We can use (5) to calculate the value of $\operatorname{PR}\left(t_{0}\right)$.

$$
\operatorname{PR}\left(t_{0}\right)=\frac{P_{\text {out }}}{P_{n}\left(t_{0}\right)}
$$

For an ideal steady photovoltaic system, the changes are synchronized between its real output power $P_{\text {out }}$ and the theoretical output of PV arrays during a certain period. Therefore, the $\operatorname{PR}\left(t_{0}\right)$ values should be similar or have minor numerical wave around a particular value while the system is operating normally in theoretical situation. The physical significance can be explained by (6).

$$
\operatorname{PR}\left(t_{0}\right)=\eta_{1} \cdot \eta_{2} \cdot \eta_{3}
$$

$\eta_{1}$ : Efficiency of PV arrays, the power loss includes loss of modules' mismatch, dust, spectral mismatch, DC transmission line, et al.;

$\eta_{2}$ : Efficiency of inverter, the power loss includes transformational loss of inverter, MPPT significance, et al.;

$\eta_{3}$ : Efficiency of grid connection, the power loss mainly contains line loss.

\section{B. Mathematical Model}

Based on the researches on the basic theories of the papers by Zekiye ERDEM [9], J. A. Ramos-Hernanz [10], M. Abdulkadir [11], Huan-Liang Tsai [12] et al., we established a practical Simulink model which will be useful for the related calculation of the PV modules, arrays and system. According to the theory, the model of PV system is shown in Fig. 1. The curve of output characteristic of PV module is shown in Fig. 2.

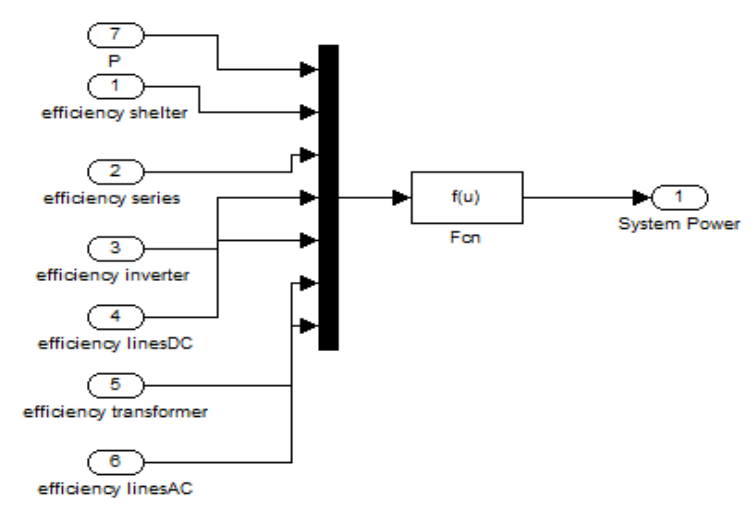

Fig. 1. Simulink model of PV system's output power.

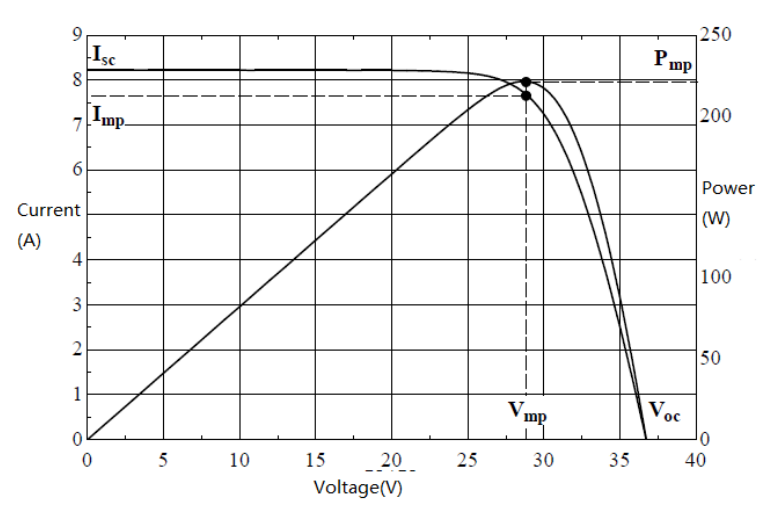

Fig. 2. Output characteristic curve of PV module.

\section{Design of Experiments}

We set up the experimental platform for research which is in Shanghai Solar Energy Research Center. The PV system is made by 8 pieces of modules, 2 small scale inverter, related test devices, et al. Besides, we designed a small scale PV system that could simulate PV power station through analysis: different situations will be introduced in next part of the article and then studied the influences on PR of PV system by 3 different factors including shadow, dust, and connection mode. We did several repetitive tests in order to ensure the accuracy of the results. The figures of experimental platform set up is as following. Refer to Fig. 3. Fig. 3(a) and Fig. 3(b) are respectively the pictures of the reverse and front side; Fig. 3(c) is the picture of the module tested in laboratory; Fig. 3(d) is the picture of the module with dust; Fig. 3(e) and Fig. 3(f) are the pictures of the system with shadow and dust. 


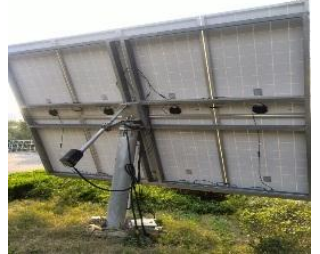

(a)

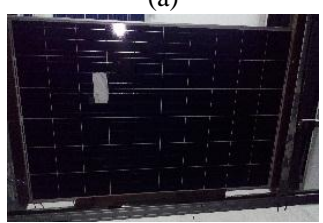

(c)

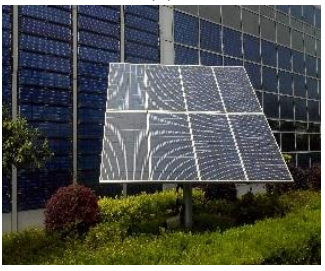

(e)

Fig. 3. Display of experimental platform.

The devices used in the experiment are as following. See Table I.

\begin{tabular}{|c|c|c|c|c|}
\hline No. & $\begin{array}{c}\text { Devices and } \\
\text { materials }\end{array}$ & Model & Manufacturer & Quantity \\
\hline 1 & PV modules & $\begin{array}{c}\text { HT60-156P-2 } \\
50\end{array}$ & HT & 8 \\
\hline 2 & Inverter & $\begin{array}{c}\text { Omniksol-1k- } \\
\text { TL }\end{array}$ & Omnik & 2 \\
\hline 3 & Actinometer & LP PYRA02 & Delta Ohm & 1 \\
\hline 4 & $\begin{array}{c}\text { Surface } \\
\text { thermometer }\end{array}$ & Testo 925 & Testo & 1 \\
\hline 5 & $\begin{array}{l}\text { Transient solar } \\
\text { simulator }\end{array}$ & $3 B$ & Pasan & 1 \\
\hline 6 & $\begin{array}{l}\text { Sensor of } \\
\text { Pasan }\end{array}$ & LT & Pasan & 1 \\
\hline 7 & $\begin{array}{c}\text { IV tester of PV } \\
\text { array }\end{array}$ & IVT-30-1000 & Kewell & 1 \\
\hline 8 & $\begin{array}{l}\text { Portable PV } \\
\text { tester }\end{array}$ & AV6593 & $\begin{array}{l}\text { The } 41^{\text {st }} \\
\text { institute of } \\
\text { CET } A L .\end{array}$ & 1 \\
\hline
\end{tabular}

\section{Experimental Scheme and Steps}

\section{1) Shadow}

Shadow is a common problem for PV system so that influence analysis of shadow on performance ratio is necessary. In order to clarify the principle of shadow, we did several relevant comparative experiments. Firstly, we tested the power loss of single module which was partly shadowed. We shadowed the system in different ways and then analyzed the influences on the system which was partly shadowed. In fact, the shadow influence on system could also be regarded as a kind of mismatch in some degree.

We shadowed the single modules as well as the system with different areas and analyzed the area shadowed influence on power loss. Moreover, we shadowed the single module with the same area but different distributions. We set up different kinds of systems that meant system in series and system in parallel and analyzed the influence of shadow.

\section{2) Connection methods of modules}

Mismatch loss exists in each PV arrays, including current loss of series-wound connection and voltage loss of shunt-wound connection. We can conclude the influence of mismatch by testing the value of performance ratio that set up with different kinds of connections.

Number of modules in series can vary from 2 to 6 in our experimental platform so that the influence of current loss on PR of PV system can be confirmed by testing the related values respectively.

Different ways of connection can be taken in order to clarify the influence of voltage loss on PR of PV system. We designed different systems for experiments with relevant connection ways, including series-wound system of which the number varies from 3 to 6 and shunt-wound system of which the arrays composed of 3 pieces of modules in each series.

\section{3) Dust}

We took the module which was exposed to outdoor for one week after the rain as the sample in shanghai and then analyzed the influence of dust on performance ratio of PV system. Single module could represent the whole system when the dust was distributed uniformly. In addition, test accuracy in laboratory is higher than that outside.

\section{RESULTS AND DISCUSSION}

\section{A. Experiments with Dust}

Dust has a great influence on the efficiency of PV system and the power loss by dust could be serious which might come to $30 \%$. The solar irradiation on the surface of the module will be weaken so that the generation capacity and the power output of PV system will decline. The concentration of dust is higher, the luminousness is lower and the solar irradiation adopted by module is lower. What's more, dust will change the form of heat transfer which may enlarge the resistance of heat transfer and influence the heat transfer of module.

TABLE II: MAXIMUM POWER OF MODULE WITH DUST

\begin{tabular}{l|lll}
\hline Series No. & $\begin{array}{l}\text { Pm before } \\
\text { cleaning/W }\end{array}$ & $\begin{array}{l}\text { Pm after } \\
\text { cleaning/W }\end{array}$ & Loss of dust \\
\hline $\begin{array}{l}\text { LCF0502-04315 } \\
\text { (Clean by water) }\end{array}$ & 242.8 & 245.3 & $-1.02 \%$ \\
$\begin{array}{l}\text { LCF0502-04795 } \\
\text { (Clean by alcohol) }\end{array}$ & 240.8 & 244.1 & $-1.35 \%$ \\
$\begin{array}{l}\text { LCF0502-04317 } \\
\text { (Clean by dry cloth) }\end{array}$ & 240.7 & 243.1 & $-0.99 \%$ \\
\hline
\end{tabular}

The maximum power of module under STC declines after the modules are cleaned. However, the characteristic of the I-V curve does change obviously. We have drawn the conclusion that dust can be regarded as a kind of uniform occlusion which will not enlarge the mismatch loss in the module. The dust occlusion on the surface of module is less harmful than the situation of which the modules are blocked partially. Refer to Table II. In this experiment, the power loss percentage of dust is about $1 \%$.

\section{B. Experiments with Shadow}

Partial shadow has a great influence on the output characteristic of photovoltaic module. For a series of cells, the output current declines with the increase of blocked area percentage. The whole output current is decided by the output 
current of the cell which was blocked. There will be no current if the cell is blocked completely because the circuit is equal to open circuit. Over than $80 \%$ power loss may occur even though the area blocked by shadow is about $10 \%$ and there will no output power if the area blocked comes to $20 \%$. The concentrate shadow has a greater influence on the output loss than the dispersive shadow if the areas of shadows are same. The characteristic curve trend is normal if the shadow is uniformly dispersed and the current between different series of cell is uneven if the shadow is not uniformly dispersed which will make the I-V curve of module be ladder-like and make multi-peak in the P-V curve appears.

The bypass diode in parallel can increase the output power, reduce the mismatch loss of photovoltaic cells, and avoid the damage caused by overheat of cells. Additionally, the increase of temperature of module that with bypass diode is less than that without bypass diode if several cells of the module are blocked. Therefore, the best way to avoid the danger of hot spot of photovoltaic cell is adding a bypass diode in parallel. However, the cost will be very high if we add a bypass diode in parallel within a cell in the actual application and we usually add a bypass diode in parallel among 10 to 18 photovoltaic cells.

The results of shadow experiments of single module are as following. Refer to Table III.

TABLE III: ELECTRIC CHARACTERISTIC VALUES OF DIFFERENT KINDS OF

\begin{tabular}{l|cccc}
\multicolumn{1}{c|}{ Shadow type } & Mpp & Vmpp & Impp & Power loss \\
\hline $\begin{array}{l}\text { LCF0502-04315-one piece } \\
\text { of cell shadowed }\end{array}$ & 160.691 & 19.825 & 8.105 & $-34.49 \%$ \\
$\begin{array}{l}\text { LCF0502-04315- half } \\
\text { piece of cell shadowed, }\end{array}$ & 170.758 & 34.347 & 4.972 & $-30.38 \%$ \\
$\begin{array}{l}\text { horizontal } \\
\text { LCF0502-04315- half } \\
\text { piece of cell shadowed, } \\
\text { vertical }\end{array}$ & 165.729 & 34.33 & 4.827 & $-32.43 \%$ \\
$\begin{array}{l}\text { LCF0502-04315-2* } \\
\text { quarter piece of cell } \\
\text { shadowed, vertical }\end{array}$ & 216.457 & 32.963 & 6.567 & $-11.75 \%$ \\
$\begin{array}{l}\text { LCF0502-04315-2* half } \\
\text { piece of cell shadowed, }\end{array}$ & 174.564 & 34.185 & 5.107 & $-28.83 \%$ \\
$\begin{array}{l}\text { vertical } \\
\begin{array}{l}\text { LCF0502-04315-quarter } \\
\text { piece of cell shadowed }\end{array}\end{array}$ & 215.444 & 32.988 & 6.531 & $-12.16 \%$ \\
\hline
\end{tabular}

The I-V curves of modules are as following. Refer to Fig. 4. Different kinds of characteristics can be concluded from these figures.

The modules used in this experiment have 3 series of cells which are in parallel. The series of cells were unable to generate electricity normally even though just one piece of cell was blocked by shadow in one piece of module due to the function of bypass diode which could make short circuit of the certain series of cells and the power loss percentage might come to $1 / 3$. We designed two different PV systems, one was set up by 4 pieces of modules which were in series and the other was set up by 6 pieces of modules which were in parallel. See Fig. 5 and Fig. 6. The variation trends of performance ratio vary with the blocked methods even though in the same photovoltaic system. Under common situation, the area blocked of module is larger so that the effect of hot spot is more outstanding, the mismatch loss of module is lager, and the attenuation degree of system is deeper. However, increasing shadow area will not enlarge the system's power loss in the condition that the subcircuit becomes short circuit and the current of backward diode flows if one subcircuit is completely shadowed. What's more, the power loss of shadow concentrated upon one cell is larger than that dispersed on several cells if the areas of shadows are same. The degree of dispersion is deeper, the loss of output power is less. The cause may be that dispersed shadow is more uniform which will reduce the mismatch loss.

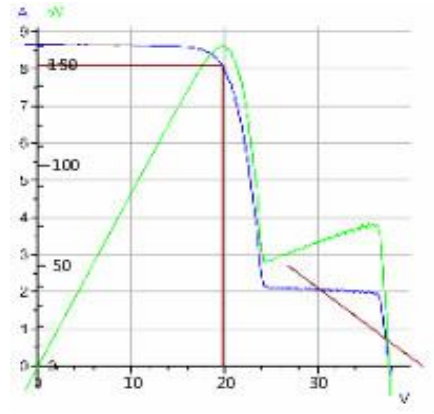

(a). LCF0502-04315-one piece of module shadowed.

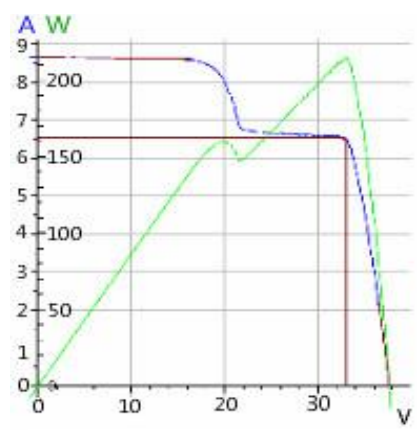

(b). LCF0502-04315-2* half piece of cell shadowed, vertical.

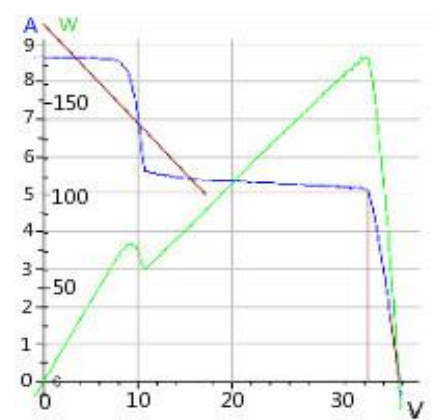

(c). LCF0502-04315-2* quarter piece of cell shadowed, vertical.

Fig. 4. Several I-V curves of modules

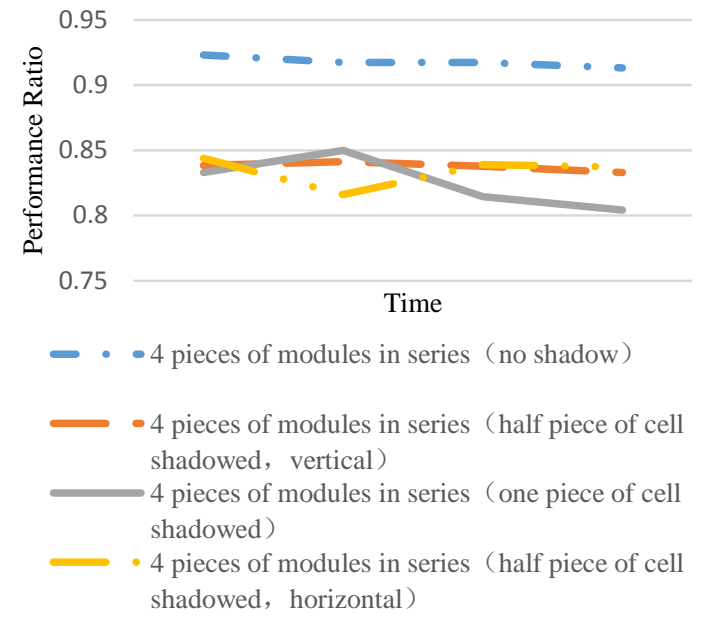

Fig. 5. PR curves of series-wound system with different kinds of shadows. 


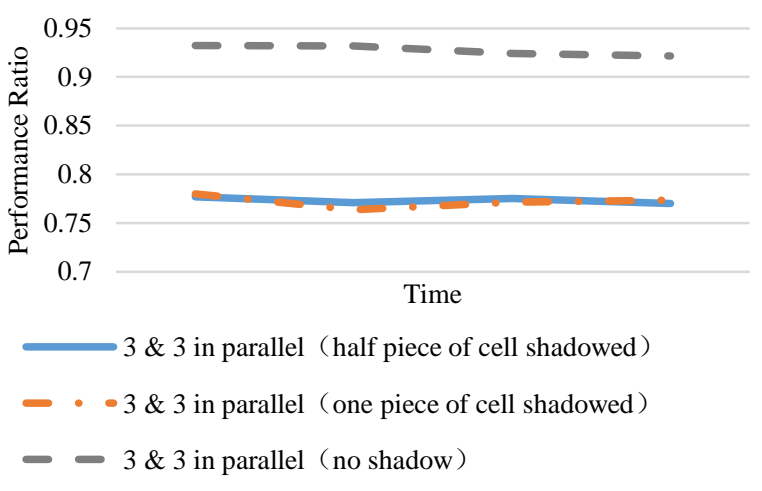

Fig. 6. PR curves of shunt-wound system with different kinds of shadows.

\section{Series-Parallel Experiments}

Contrast the performance ratio of different systems as shown in Fig. 7, the PR value of 3-module series-wound system is larger than that of 4-module series-wound system. Compared with the 4-module system, the 3-module system has less modules, mismatch loss, and line loss so that the efficiency and PR value will increase according with the theoretical analysis. However, the PR value of 6-module series-wound system is larger than that of 4-module series-wound system. Analysis of possible reason is that inverter mismatch loss exists. The photovoltaic system is set up by modules and one $1 \mathrm{~kW}$-inverter. Under natural conditions, the common irradiance of the experimental platform in Shanghai Solar Energy Research Center in May varies from 500 to $800 \mathrm{~W} / \mathrm{m}^{2}$ which is up to the Standard Test Condition: $1000 \mathrm{~W} / \mathrm{m}^{2}$. The total power of 6 pieces of modules is about $1000 \mathrm{~W}$ which is matched with inverter and the total power of 4 pieces of modules is approximately $700 \mathrm{~W}$ which has a large mismatch with the inverter. Therefore, the PR value of 6-module series system is larger than that of 4-module series-wound system. Last but not the least, contrast the PR curves in these 3 figures, for the photovoltaic systems with same components, the one in series has higher efficiency than that in parallel if the same kind of shadow exists. In previous experiments, the modules are same, the line loss can be regarded as the same, and the mismatch losses of inverters can also be regarded as the same. Different kinds of mismatch losses may cause this phenomenon, the one in series is caused by current mismatch loss and the one in parallel is caused by voltage mismatch loss. In other words, the current mismatch loss has a larger effect on the performance ratio of photovoltaic system than the voltage mismatch loss.

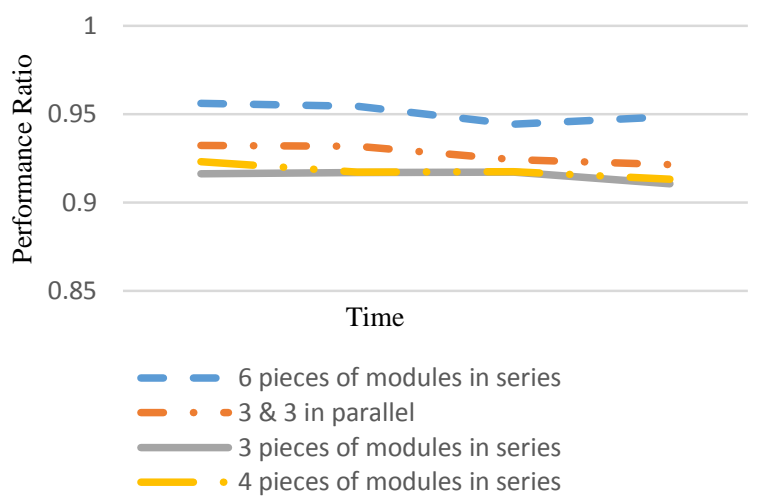

Fig. 7. PR curves of series-parallel system with different kinds of connection.

\section{CONCLUSION AND RECOMMENDATION}

\section{A. Conclusion}

Through the study, we did in this paper, preliminary conclusion can be drawn that:

1) If the module has larger shadowed area, its hot spot effect is more remarkable and mismatch loss of the module is larger so that heavier power loss will occur. Shadowing one cell of 60pcs-module may cause $30 \%$ loss of power. Generated shadow has a larger influence on the output characteristics of the module than dispersed shadow when the areas of shadows are the same. That is to say, the output power loss of the module with the same area of generated shadow is much more than that dispersed on different series of cells in parallel.

2) The shadow has the same kind of influence on series-parallel photovoltaic system as the photovoltaic module. Two-peak ladder I-V curve and two-peak P-V curve of module will be caused by shadow and multiple local maximum power points of the photovoltaic system exist so that the efficiency of the system reduces. $1 \%$ shadowed area could cause $10 \%$ power loss for series-wound system and $15 \%$ power loss for shunt-wound system in our experimental platform which was set up in Shanghai Solar energy Research Center.

3) For series-parallel photovoltaic system, power loss caused by shadow also belongs to one kind of series-parallel mismatch loss in some degree. Different methods of series-parallel connections will cause different extent of system's efficiency losses. Ignore the effect of inverter loss, less modules of photovoltaic system will cause less mismatch loss as well as less line loss of photovoltaic system which will affect the performance ratio of photovoltaic system. What's more, the current mismatch loss has a larger influence on the system than the voltage mismatch loss so that the PR value of series-wound system is larger than that of shunt-wound system. The maximum difference among various connection methods may come to $4 \%$.

4) Under normal circumstances, the longer time of accumulating dust will cause the more power loss of system. The dust loss of module will reach $1 \%$ after one-week ash deposition if the module is clean originally in May of Shanghai. The dust on the PV arrays of photovoltaic power station should be cleaned regularly in order to insure the good performance of system.

\section{B. Recommendation}

The transient performance evaluation index $\operatorname{PR}\left(t_{0}\right)$ can be regarded as a very important parameter during the process of PV system's design and real-time monitoring. In addition to benefit the design of photovoltaic system and the operation of later maintenance work, this technical parameter can be the professional base for investment evaluation of photovoltaic power station.

Various factors may affect the operation stability of photovoltaic system. The transient performance evaluation index $\operatorname{PR}\left(t_{0}\right)$ is just a parameter that could reflect the system's health degree rather than improving the performance of system itself. We will have to analyze the relationship among $\eta_{1}, \eta_{2}, \eta_{3}$ in equation (6) and the $\operatorname{PR}\left(t_{0}\right)$ values in different time points through researching the uncertainty of transient 
performance evaluation index $\mathrm{PR}\left(\mathrm{t}_{0}\right)$. Comprehensive model considering relevant influence factors of performance ratio values and the relationships among them will be built. The key to solve actual problem is that analyzing the specific influence indexes of each factors on the system quantitatively by repeatedly verifying and improving the model built which is testified in different scales and types of photovoltaic systems.

\section{ACKNOWLEDGMENT}

The authors wish to acknowledge the support of Shanghai Solar Energy Research Center in conducting this work.

\section{REFERENCES}

[1] Carol. (April 2015). Quietly changed global photovoltaic market: China's new installed PV capacity in 2014 has become No.1 of the world (in Chinese). [Online]. Available: http://news.solarbe.com/201504/17/68385.html

[2] Photovoltaic System Performance Monitoring - Guidelines for Measurement, Data Exchange and Analysis, IEC Standard 61724: 1998.

[3] Update on Edition 2 of IEC 61724: PV System Performance Monitoring, Feb. 2014.

[4] M. J. Adinoyi and S. A. M. Said, "Effect of dust accumulation on the power outputs of solar photovoltaic modules," Renewable Energy, vol. 60, pp. 633-636, July 2013.

[5] M. Mani and R. Pillai, "Impact of dust on solar photovoltaic (PV) performance: Research status, challenges and recommendations," Renewable and Sustainable Energy Reviews, vol. 14, pp. 3124-3131, July 2010.

[6] J. K. Kaldellis and M. Kapsali, "Simulating the dust effect on the energy performance of photovoltaic generators based on experimental measurements," Energy, vol. 36, pp. 5154-5164, July 2011.

[7] E. Kymakis, S. Kalykakis, and T. M. Papazoglou, "Performance analysis of a grid connected photovoltaic park on the island of Crete,' Energy Conversion and Management, vol. 50, pp. 433-438, Jan. 2009.

[8] M. Z. Hussin, A. M. Omar, Z. M. Zain, and S. Shaari, "Performance of grid-connected photovoltaic system in equatorial rainforest fully humid climate of Malaysia," International Journal of Applied Power Engineering, vol. 2, no. 3, pp. 105-114, Dec. 2013.

[9] Z. Erdem and M. B. Erdem, "A proposed model of photovoltaic module in Matlab/Simulink ${ }^{\mathrm{TM}}$ for distance education," Procedia Social and Behavioral Sciences, vol. 103, pp. 55-62, Oct. 2013.

[10] J. A. Ramos-Hernanz, J. J. Campayo, J. Larranaga, E. Zulueta, O. Barambones, J. Motrico et al., "Two photovoltaic cell simulation models in Matlab/Simulink," International Journal on Technical and Physical Problems of Engineering, vol. 4, no. 1, pp. 45-51, Mar. 2012.

[11] M. Abdulkadir, A. S. Samosir, and A. H. M. Yatim, "Modeling and simulation based approach of photovoltaic system in Simulink model," ARPN Journal of Engineering and Applied Sciences, vol. 7, no. 5, pp 616-623, May 2012.
[12] H.-L. Tsai, "Insolation-oriented model of photovoltaic module using Matlab/Simulink," Solar Energy, vol. 84, pp. 1318-1326, May 2010.

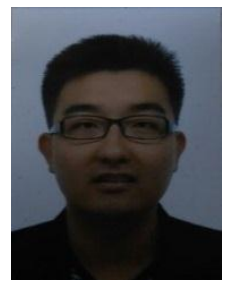

Qingguo Xu was born in Jiangsu, China on Jan. 12, 1991. He is now a postgraduate student majoring in materials science and engineering with East China University of Science and Technology in Shanghai, China. His current research focuses on photovoltaic technologies and systems.

$\mathrm{He}$ has become a part-time R\&D engineer considering photovoltaic systems in Shanghai Solar Energy Research Center since May 2014.

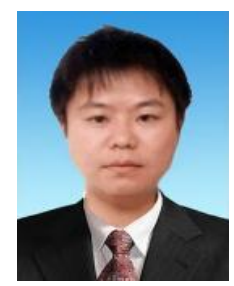

Hongbo Li was born in Shanxi, China in July 1973 $\mathrm{He}$ is now a professor in the field of new energy materials and devices in East China University of Science and Technology in Shanghai, China. His current research focuses on photovoltaic materials, devices, systems, distributed energy, and the technologies considering smart grid.

He worked as the leader of Shanghai Solar Energy Research Center from Apr. 2002 to Jun. 2012 and he became the chief technology officer of Hareon Solar, Ltd since then. He has taken over several national projects about photovoltaic technologies and achieved significant achievements.

Prof. Li has owned invention patent award of Shanghai and advanced technology individual of Shanghai Expo. Besides, Prof. Li is the vice director of Shanghai Solar Energy Association and the deputy director of China Renewable Energy Institute.

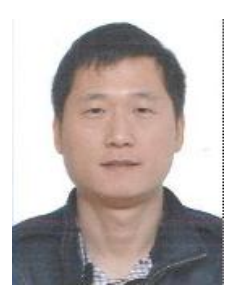

Guoqiang Hao was born in Hebei, China on Mar. 11, 1977. He is now a senior engineer in the new energy materials and devices in East China University of Science and Technology in Shanghai, China. His current research focuses on the design and operating maintenance of photovoltaic systems and the relevant theories of micro electric network.

$\mathrm{He}$ worked as the main technical official of Shanghai Solar Energy Research Center from Mar. 2006 to Aug. 2013 and he became operating maintenance director of Hareon Solar, Ltd since then. He has taken over several provincial projects about photovoltaic demonstrative systems

Dr. Hao has owned the second class prize of Shanghai Advanced Science and Technology twice.

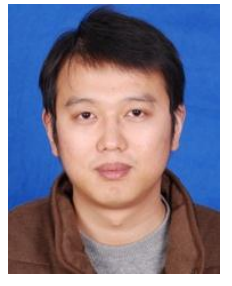

Yefei Ding was born in Jiangsu, China on Mar. 26, 1985. He graduated from the Department of Physical Power supply of the Institute of Space Technology as a master in Mar. 2010, Shanghai, China.

He has worked for about 6 years as a QA engineer in Shanghai Solar Energy Research Center. He is now the manager of the Testing Department of Shanghai Solar Energy Research Center and his current research focuses on the testing technologies and devices. 